\title{
O sujeito adolescente e a intervenção psicanalítica: notas a partir de um caso clínico*1
}

\author{
Leônia Cavalcante Teixeira*2
}

\begin{abstract}
Este artigo versa sobre as vicissitudes subjetivas e institucionais das medidas sócioeducativas a partir das interfaces entre os estudos sobre a subjetividade nos campos da Psicanálise e do Direito. $O$ adolescer é analisado a partir dos paradoxos e enigmas estruturantes que se instauram no processo de constituição subjetiva, sendo privilegiado como momento lógico a partir da construção de um caso clínico que interroga as intervenções junto ao sujeito adolescente no campo nebuloso de interface entre Psicanálise e Direito. A perversão social consiste no foco da discussão teórico-clínica, sendo o conceito que fez trabalhar a possibilidade de uma clínica psicanalítica quando indicações jurídicas não consideram as vicissitudes subjetivas.
\end{abstract}

Palavras-chave: Adolescência, perversão social, caso clínico, medidas socioeducativas

*1 Trabalho apresentado no Colóquio Internacional sobre a Metapsicologia da Perversão. Laços Sociais da Perversão, realizado em Recife, PE, nos dias 26, 27 e 28 de agosto de 2013.

*2 Universidade de Fortaleza - Unifor (Fortaleza, CE, Br). 
A adolescência, como etapa do ciclo vital, é desnaturalizada, não consistindo em um quadro de características imutáveis, mas construídas, inclusive o próprio conceito, forjado na modernidade e não reduzível a aspectos orgânicos e fisiológicos, mesmo que o processo pubertário invada o sujeito e exija dele posições diferentes das assumidas quando criança (Rassial, 1997; Saggese, 2000). A adolescência confronta o sujeito com o real do sexo e as implicações daí advindas, como um posicionamento frente à diferença anatômica dos sexos (Richard, 1998; Rassial, 2000, 2005).

Considerando a distinção entre puberdade e adolescência, numa abordagem histórica do conceito de adolescência e adolescente (Lesourd, 2004), o adolescente é vislumbrado como sujeito em passagem, tendo exigências psicossociais a cumprir na saída da infância e elaboração dos lutos a ela decorrentes, e aspiração, primeiramente no âmbito dos ideais sociais, às posições no espaço da família, do trabalho e da relação com a Lei e seus pares (Rassial, 1997, 2000, 2005).

\section{Quando o ato infracional embaraça a construção idealizada sobre $o$ adolescente}

Apresentamos Perséfone, 16 anos, encaminhada para acompanhamento psicológico pela Vara da Infância e Juventude em consultório particular, já que a família tinha recursos financeiros e não precisava recorrer às instituições públicas. Perséfone, entre menina e mulher, cometera furtos tendo sido surpreendida pela polícia e enviada à "Justiça" como nos contou. Os pais a trazem ao consultório e explicam que a indicação de terapia fora a condição para que não cumprisse medidas socioeducativas, o que a "exporia demais". Acompanho Perséfone por dois meses e concluo que, por meio de contatos constantes com a Vara da Infância e da Juventude, devo 
encaminhar, após trabalhar com a adolescente, perdida entre as demandas familiares de se comportar bem como os outros irmãos e o dado clínico de que ela achava normal furtar o que não lhe era possibilitado pela família, já que tinha "dinheiro" e não lhe dava por implicância.

O processo terapêutico de Perséfone e a escuta de seus pais nos mostraram o quanto a jovem mulher se encontrava enodada por marcas familiares não elaboradas psiquicamente por personagens significativos para a constituição do que os pais, mais particularmente o pai, nominavam "o que nossa família significa para a sociedade". Havia uma rede de não ditos e mal ditos que circundava os herdeiros de um patrimônio do qual não podiam usufruir por não poderem conhecer, sendo porém a Perséfone e seus irmãos esperado que compartilhassem de um "orgulho familiar", nas palavras do pai, que deveria ser vivenciado como privilégio. Aliás, era dito à paciente, desde pequena, que participar dessa família a diferenciava das colegas, pois elas não tinham esse privilégio. As sessões com os pais, ora separados, ora juntos, eram cheias de uma aura de penumbra e fôra a mãe e seus atos falhos que abriram espaços possíveis para a existência de Perséfone fora da rede imaginária que a aprisionava. A partir da escuta do que escapava do compromisso familiar de "se apresentarem bem à sociedade", Perséfone foi tendo existência por sua fala e construindo um mito neurótico diferente das montagens perversas familiares, propagadas sem questionamento inicialmente por ambos os pais e, depois à iluminação que a fala de sua mãe deu rareando a penumbra e deixando à vista segredos da família paterna, ainda pelo pai insistente em sustentar um castelo que se desmoronava e que fôra Perséfone pela via da repetição colocada em ato que abriu ao social.

À medida que a paciente se apoderava de uma história sua e se responsabilizava por ela, no processo analítico, aspectos relacionados aos encaminhamentos do poder judiciário foram se clareando até quando a analista pontuou sobre a possibilidade de ela ter de se responsabilizar pelos atos delituosos que cometera e que não era na análise que faria isso, pois algo restava, na própria fala de Perséfone, de uma dívida a ser paga.

Assim, com o conhecimento de Perséfone, resolvemos encaminhar à equipe da instituição jurídica, um relatório solicitando que as medidas socioeducativas fossem cumpridas. Essa decisão, depois de um processo de argumentação pela analista, foi acatada pelo juiz que encaminhou Perséfone, contra a vontade dos pais de "exporem" a filha a situações constrangedoras, a uma instituição beneficente que tem como foco o apoio a crianças em risco psíquico e social de classe social baixa, "muito mais baixa que a de Perséfone", assim exclamava o pai, revoltado com a mudança nos encaminhamentos judiciais.

Se a produção de subjetividades é influenciada por fatores externos psíquicos, não se pode esquecer que fatores externos auxiliam e influenciam também no estabelecimento 
e desenvolvimento do processo de subjetivação. Neste encontram-se inseridas vertentes tais como a autoestima, a autoconfiança e o autorrespeito resultantes de trocas nas relações intersubjetivas, acolhidas e suportadas não só por aspectos que vão desde o amor, como também pelas relações jurídicas e de estima social, nas quais o Estado participa na tarefa de formação de indivíduos capazes. (Szpacenkofp, 2011, p. 18)

Nesse sentido, o Estado e suas instituições exercem um papel fundamental quando têm em suas atribuições o estabelecimento e o fazer cumprir deveres e ser beneficiário de direitos. Quando Perséfone se dá conta daquilo que os representantes da Justiça não puderam sustentar, qual seja, o cumprimento por ela das medidas supostas pelo Estado quando certas regras são violadas, foi de um lugar diverso do da lógica perversa que os membros de sua família para se fazerem presentes participavam.

Szpacenkofp (2011) escreve sobre o momento civilizatório atual como "um panorama em que fortes indícios de ingerência da perversão social são identificados, por meio dos quais não só a derrocada da lei é disseminada, como passa a funcionar o projeto de dessubjetivação do outro (p. 21). Ao abordar a perversão como social e não somente como estrutura psíquica, podemos pensar sobre a lei a partir das relações entre o universal e o singular, inclusive, ainda com Szpacenkofp:

sabemos que a lei é perversa, na medida em que a parte é universalizada enquanto todo. É possível que todas as leis concretizem com seu enunciado uma parte excluída, uma parte condenada pela própria lei. A atuação da perversão, como transgressão da lei, na medida em que esta não é aplicada ou aceita, e muito menos respeitada, faz surgir o buraco que passa a ser completado por qualquer um ou qualquer coisa, ou mesmo por outra lei. (p. 24)

\section{À escuta dos ruídos nas interfaces entre Psicanálise e Direito}

O campo da assistência social ocupa lugar de importância nas políticas públicas, cabendo aos profissionais que lidam com o cotidiano dos que padecem entre os limites entre exclusão e inclusão sociais problematizá-lo.

Especificamente as medidas socioeducativas e a atribuição identitária "adolescente em conflito com a lei” são aqui questionadas quando não acompanhadas de uma discussão sobre as vicissitudes dos adolescentes normatizados pelos ditos jurídicos e acompanhados no âmbito da assistência social. Rosa et al. (2013, p. 75), ao discutirem a clínica no contexto institucional, ressaltam que "a cena psicanalítica depara-se com a cena sociopolítica, aparentemente distante nos consultórios, e é posta à prova pelos atravessamentos diretos que põem em xeque a possibilidade de sustentação do trabalho analítico". 


\section{ARTIGOS}

Considerando as leituras que a psicanálise de Freud e de Lacan fazem sobre a constituição do singular e do coletivo concomitantemente, em interdependência, pensamos que a problematização dos vieses nas interfaces entre os discursos e práticas que privilegiam a subjetividade e o jurídico consistem em um panorama de análise e encaminhamento de casos que, tomados pelo âmbito jurídico, carecem de leituras e intervenções subjetivas.

A psicanálise, quando engajada nas questões sociais e em diálogo com campos dela distintos, como o Direito, ocupa um lugar importante ao se debruçar sobre áreas delicadas, especialmente quando tangem à criança e ao adolescente e, em especial, ao atendimento psicanalítico sem prévia demanda, como no caso de Perséfone.

Balizados pelos campos de apreensão da subjetividade - entendida como singular e coletiva indistintamente - pensamos que devemos privilegiar a ética na construção do adolescente e não meramente normatizar por nomenclaturas como "em conflito com a lei".

Consideramos que muito já vem sendo feito, muitas conquistas frutas de lutas de diversas áreas da psicologia, porém, reiteramos que a normatização subjetiva colada ao adolescente com o rótulo "adolescente autor de ato infracional" precisa ser mediada por um trabalho de responsabilização do sujeito frente ao ato que cometeu infringindo as normas que regem o convívio social. Sugerimos que possamos analisar os efeitos subjetivos das nomenclaturas que, oferecidas pelo Poder Judiciário, e outorgadas pela família, escola, por exemplo, aprisionam o sujeito pela via da identidade no lugar de excluído, mesmo quando as intervenções propostas visem à inclusão social.

Com Perséfone aprendemos que "poupá-la" da exposição pública ao cumprir medidas socioeducativas a excluía da lei à qual todos nós estamos submetidos e a desresponsabiliza pelos seus atos, mantendo-a ilusoriamente incluída em um espaço familiar cúmplice, porém excluindo-a do campo do social, tomado de modo mais amplo, espaço social e coletivo regido por leis e normas.

Quando saberes e práticas acerca dos processos de inclusão/exclusão sociais são vislumbrados de modo interdisciplinar, podemos construir ferramentas teóricas e estratégias de intervenção junto a sujeitos em situação de vulnerabilidade social e psíquica, entendendo que vulnerabilidade social não diz só respeito à escassez de condições financeiras.

Considerando que as políticas de saúde e de assistência focalizam como metas, a construção da autonomia como base para a cidadania, resta-nos interrogar sobre como atuar a partir desse ideário, porém considerando as singularidades do cotidiano dos sujeitos como agentes sociais. Pensamos que a dinâmica inclusão/ exclusão é complexa exigindo reflexões não reducionistas, visando não correr o risco de ratificarmos a perversão comum, tal qual nomeado por Lebrun (2010). 
Agradecemos a Perséfone por nos fazer apreender que ao estar incluída de acordo com a família, excluída estava do campo coletivo, das normas que regem a vida social, além de não ser responsabilizada pelos seus atos, condição para a autonomia e cidadania.

\section{Referências}

Lebrun, J.-P. (2010). A perversão comum; viver juntos sem outro. Rio de Janeiro: Cia. de Freud.

Lesourd, S. (2004). A construção adolescente no laço social. Rio de Janeiro: Cia. de Freud.

Rassial, J.J. (1997). A passagem adolescente: da família ao laço social. Porto Alegre: Artes e Ofícios.

Rassial, J.J. (2000). O sujeito em estado limite. Rio de Janeiro: Cia. de Freud.

Rassial, J.J. (2005). O adolescente e o psicanalista. Rio de Janeiro: Cia. de Freud. (Trabalho original publicado em 1999).

Richard, F. (1998). Les troubles psychiques à l'adolescence. Paris: Dunot.

Rosa, M. D. et al. (2013). Clínica e Política interrogadas pelo ato infracional: a construção do caso. In J. de Moreira, C. Guerra, J. M. P. Souza (Orgs.). Diálogos com o campo das medidas socioeducativas: conversando sobre a justiça, o cotidiano do trabalho e o adolescente (pp. 75-92). Curitiba: CRV.

Saggese, E. (2000). Adolescência e modernidade. In Congresso Internacional de Psicanálise e suas Conexões, 1999, Anais, Rio de Janeiro: Cia. de Freud. p. 253-259.

Szpacenkopf, M. I. O. (2011). Perversão social e reconhecimento na atualidade. Rio de Janeiro: Garamond.

\section{Resumos}

(The adolescent subject and psychoanalytic intervention: notes based on a clinical case)

This paper focuses on the subjective and institutional vicissitudes of socioeducational measures based on interfaces between studies on subjectivity in the fields of psychoanalysis and law. Adolescence is analyzed on the basis of structuring paradoxes and enigmas that are established in the process of the constitution of the subject and can be seen as a logical moment. The argument here is based on a clinical case that involves interventions with an adolescent subject in the hazy field of the interface between psychoanalysis and law. The topic of the theoretical and clinical discussion is social perversion, as it is the concept that sets into motion the possibility of psychoanalytic clinic when legal indications fail to note subjective conflicts.

Key words: Adolescence, social perversion, clinical case, social-correctional measures 


\section{ARTIGOS}

(Le sujet adolescent et l'intervention psychanalytique: notes à partir d'un cas clinique)

Cet article discute les vicissitudes subjectives et institutionnelles des mesures socio-éducatives à partir des interfaces entre les études sur la subjectivité dans les domaines de la Psychanalyse et du Droit. Le processus de l'adolescence est analysé à partir des paradoxes et des énigmes qui le structurent et qui se présentent dans le processus de la constitution subjective, privilégié comme moment logique à partir de la construction d'un cas clinique qui met en question les interventions auprès de l'adolescent dans le domaine flou de l'interface entre la Psychanalyse et le Droit. La perversion sociale se retrouve au centre de la discussion théorico-clinique en tant que concept qui permet la possibilité d'une clinique psychanalytique lorsque les décisions juridiques ne prennent pas en compte les vicissitudes subjectives.

Mots clés: Adolescence, perversion sociale, cas clinique, mesures socio-éducative

(El sujeto adolescente y la intervención psicoanalítica: notas de un caso clínico)

Este artículo se centra en las vicisitudes subjetivas e institucionales de las medidas educativas a partir del análisis de las interfaces entre los estudios sobre la subjetividad en el campo del Psicoanálisis y del Derecho. El adolecer es analizado desde las paradojas y enigmas estructurantes que instauran el proceso de constitución subjetiva, privilegiando como momento lógico la construcción de un caso clínico que cuestiona las intervenciones junto al sujeto adolescente en el campo nebuloso de interface entre el psicoanálisis y el derecho. La perversión social es el foco de la discusión teórica y clínica que, como concepto, posibilitó trabajar una clínica psicoanalítica cuando indicaciones jurídicas no consideran las vicisitudes subjetivas.

Palabras clave: Adolescencia, perversión social, caso clínico, medidas socio-educativas

(Das jugendliche Subjekt und die psychoanalytische Intervention: Beobachtung eines klinischen Falls)

In diesem Beitrag geht es um die subjektiven und institutionellen Schicksale der sozial-bildenden Maßnahmen. Es wird von den Schnittstellen zwischen durchgeführten Studien zur Subjektivität im Bereich der Psychoanalyse und des Rechts ausgegangen. Die Entwicklungen im Teenageralter werden aufgrund der strukturierenden Paradoxe und Rätsel untersucht, die sich in diesem Prozess der subjetkiven Bildung einstellen. Es wird vorzüglich als ein logischer Moment behandelt, ausgehend von der Strukturierung eines klinischen Falls, der die Interventionen bezüglich eines Teenager-Subjektes im nebulösen Bereich der Schnittstelle zwischen Psychoanalyse und Recht hinterfragt. Die soziale Perversion besteht im Fokus der theoretisch-klinischen Diskussion, wobei der Begriff zur Erarbeitung der Möglichkeit einer psychoanalytischen Klinik beiträgt, während rechtliche Empfehlungen die subjektiven Schicksale nicht mit in Betracht ziehen.

Schlüsselwörter: Teenageralter, soziale Perversion, klinischer Fall, sozial-erzieherische Massnahmen

Rev. Latinoam. Psicopat. Fund., São Paulo, 17 (3-Suppl.), 797-804, set. 2014 
ioCitação/Citation: Teixeira, L. C. (2014, setembro). O sujeito adolescente e a intervenção psicanalítica: notas a partir de um caso clínico. Revista Latinoamericana de Psicopatologia Fundamental, 17(3-Suppl.), 797-804.

Editor do artigo/Editor: Prof. Dr. Manoel Tosta Berlinck

Recebido/Received: 15.3.2014/ 3.15.2014 Aceito/Accepted: 15.4.2014 / 4.15.2014

Copyright: (C) 2009 Associação Universitária de Pesquisa em Psicopatologia Fundamental/ University Association for Research in Fundamental Psychopathology. Este é um artigo de livre acesso, que permite uso irrestrito, distribuição e reprodução em qualquer meio, desde que o autor e a fonte sejam citados / This is an open-access article, which permits unrestricted use, distribution, and reproduction in any medium, provided the original author and source are credited.

Financiamento/Funding: A autora declara não ter sido financiada ou apoiada / The author have no support or funding to report.

Conflito de interesses/Conflict of interest: A autora declara que não há conflito de interesses / The author has no conflict of interest to declare.

\section{Leônia Cavalcante Teixeira}

Professora Titular do Programa de Pós-Graduação em Psicologia da Universidade de Fortaleza - Unifor (Fortaleza, CE, Br); Doutora em Saúde Coletiva com Pós-Doutorado em Psicologia; Bolsista Produtividade Conselho Nacional de Desenvolvimento Científico e Tecnológico - CNPq (Brasília, DF, Br); Psicanalista.

Rua Henriqueta Galeno, 1080/2301 - Dionísio Torres

60135-420 Fortaleza, CE, Br

e-mail: leonia.ct@gmail.com 